\title{
A Large-Scale Multibody Manipulator Soft Sensor Model and Experiment Validation
}

\author{
Wu Ren, Yunxin Wu, Zhaowei Zhang, and Fan Hu \\ State Key Laboratory for High Performance Complex Manufacturing, College of Mechanical and Electrical Engineering, Central South \\ University New Campus, B-405 Room of Electrical and Mechanical Buildings, Changsha, Hunan 410083, China
}

Correspondence should be addressed to Yunxin Wu; wuyunxin@csu.edu.cn

Received 24 September 2013; Revised 15 November 2013; Accepted 26 December 2013; Published 6 February 2014

Academic Editor: Shahram Payandeh

Copyright ( $2014 \mathrm{Wu}$ Ren et al. This is an open access article distributed under the Creative Commons Attribution License, which permits unrestricted use, distribution, and reproduction in any medium, provided the original work is properly cited.

\begin{abstract}
Stress signal is difficult to obtain in the health monitoring of multibody manipulator. In order to solve this problem, a soft sensor method is presented. In the method, stress signal is considered as dominant variable and angle signal is regarded as auxiliary variable. By establishing the mathematical relationship between them, a soft sensor model is proposed. In the model, the stress information can be deduced by angle information which can be easily measured for such structures by experiments. Finally, test of ground and wall working conditions is done on a multibody manipulator test rig. The results show that the stress calculated by the proposed method is closed to the test one. Thus, the stress signal is easier to get than the traditional method. All of these prove that the model is correct and the method is feasible.
\end{abstract}

\section{Introduction}

Large-scale multibody manipulators often work in harsh conditions. Due to the frequently posture change, they are susceptible subject to vibration and shock. The structure stress increased during the working process. Thus, obtaining the structure stress information is significant in health monitoring of these machineries. The existing structure stress signal is obtained by pasting strain sensors onto the structures. However, the strain sensors are easily damaged and usually have short lifespan. The operators need to frequently repaste them during working process. Therefore, the cost increases largely and it is not suitable for long-term health monitoring.

In the recent researches, Cazzulani et al. proposed a health monitoring algorithm for concrete displacing booms. The method is based on geometrical and dynamic knowledge by estimating the boom failure through a self-learning program. And the stress signals are got by pasting sensors onto the structure $[1,2]$. Cazzulani et al. selected a 4-section boom mobile concrete pump truck and analyzed the load characteristics of them. Then, the boom damage was calculated by stress signal [3]. Sun et al. used a closed-loop detection and open-loop control strategy on the vibration suppression of a truck-mounted concrete displacing boom using angle signals [4]. Liu et al. calculated a truck mounted concrete boom dynamics characteristic using Lagrange principle and did the experiment on a commercial one which proved that the simulation model was correct [5]. Soft sensor method is also used in other fields. Facco et al. provided quality estimation by multivariate statistical soft sensor and got accurate measured results by it [6]. McElroy et al. provided a discrete element method (DEM) model of a rotating drum and used soft sensor method to detect the flow regime of it [7]. Deng et al. used soft sensors technology to build a data-driven model and provided online continuous prediction of specific variables [8]. Wang et al. proposed a soft sensor modeling algorithm with partial least squares. The approach is used in stationary and nonstationary behaviors monitoring of a blast furnace hearth wall and has good results [9].

Soft sensor technology is used to obtain variable information which is difficult to be directly measured through parameters which are easy to obtain $[10,11]$. This paper is organized as follow: Section 2 presents the boom structure of the test rig. Section 3 establishes the mathematical relationship between the booms and hydraulic cylinders. In Section 4 , the soft sensor model of the boom test rig has been built. In the model, main variable is stress signal and auxiliary variable is angle signal. Section 5 gives the simulation and 


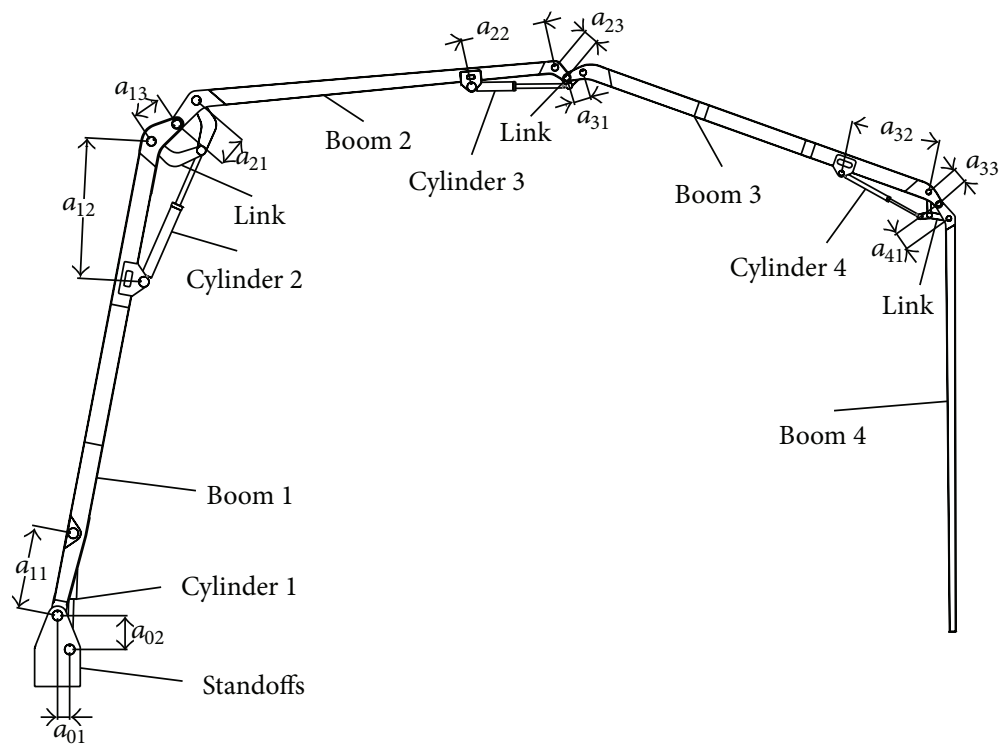

FIgURE 1: Multibody manipulator structure model and joint distance.

TABLE 1: Multibody manipulator parameters.

\begin{tabular}{|c|c|c|c|c|c|c|}
\hline Boom & Length (m) & Angle $\left(^{\circ}\right)$ & Boom weight $(\mathrm{N})$ & Boom bending angle $\left({ }^{\circ}\right)$ & $\begin{array}{c}\text { Distance between } \\
\text { joints }(\mathrm{m})\end{array}$ & $\begin{array}{c}\text { Hydraulic cylinders } \\
\text { weight }(\mathrm{N})\end{array}$ \\
\hline 1 & $L_{1}$ & $\theta_{1}$ & $G_{1}$ & $\gamma_{12}$ & $a_{11}, a_{12}, a_{13}$ & $G g_{1}$ \\
\hline 2 & $L_{2}$ & $\theta_{2}$ & $G_{2}$ & $\gamma_{21}, \gamma_{22}$ & $a_{21}, a_{22}, a_{23}$ & $G g_{2}$ \\
\hline 3 & $L_{3}$ & $\theta_{3}$ & $G_{3}$ & $\gamma_{31}, \gamma_{32}$ & $a_{31}, a_{32}, a_{33}$ & $\mathrm{Gg}_{3}$ \\
\hline 4 & $L_{4}$ & $\theta_{4}$ & $G_{4}$ & $\gamma_{41}$ & $a_{41}$ & $G g_{4}$ \\
\hline
\end{tabular}

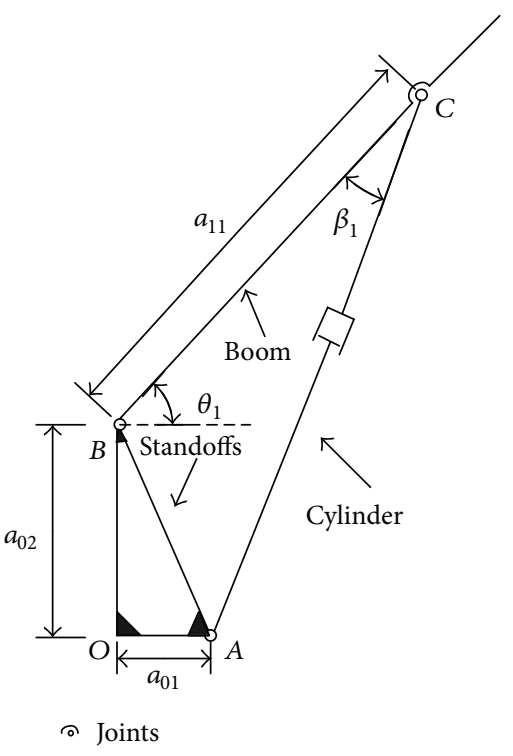

FIgURE 2: Connection relationship between the first boom and the hydraulic cylinder.

test results of the test points' stress which proofs that the proposed model is correct. The stress information of two typical working conditions is calculated from angle signals then. Finally, conclusion is presented in Section 6. All of these provide real-time health monitoring for such mechanisms.

\section{Multibody Manipulator Model and Parameters}

The structure model is shown in Figure 1. In the model, the multibody manipulator consists of 4 booms, several links, 4 hydraulic cylinders, and standoffs. The postures transformation is achieved by luffing mechanisms which are driven by corresponding hydraulic cylinders. The joints distance is expressed as $a_{i j}(i=0,1,2,3,4 ; j=1,2,3,4)$. The physical parameters of the structure are shown in Table 1.

\section{Boom Hydraulic Cylinder Model}

3.1. The First Boom Cylinder Model. The first boom and standoffs are shown in Figure 2. The angle between the cylinder and boom is $\beta_{1}$ and the cylinder length is $l_{1}$. They can be solved by

$$
\angle O A B=\arctan \left(\frac{a_{02}}{a_{01}}\right),
$$


TABLE 2: Multibody manipulator luffing mechanism parameters.

\begin{tabular}{cccccc}
\hline Boom & Length of links $(\mathrm{m})$ & Length of cylinders $(\mathrm{m})$ & $\begin{array}{c}\text { Angles between } \\
\text { cylinders and booms }\left(^{\circ}\right)\end{array}$ & $\begin{array}{c}\text { Angles between } \\
\text { booms and links }(\mathrm{m})\end{array}$ & $\begin{array}{c}\text { Angles between } \\
\text { links }\left({ }^{\circ}\right)\end{array}$ \\
\hline 1 & $b_{11}, b_{12}$ & $l_{2}$ & $\beta_{2}$ & $\alpha_{12}, \alpha_{21}$ & $\phi_{1}$ \\
2 & $b_{21}, b_{22}$ & $l_{3}$ & $\beta_{3}$ & $\alpha_{22}, \alpha_{31}$ & $\phi_{2}$ \\
3 & $b_{31}, b_{32}$ & $l_{4}$ & $\beta_{4}$ & $\alpha_{32}, \alpha_{41}$ & $\phi_{3}$ \\
\hline
\end{tabular}

TABLE 3: Boom variables of the stress calculation.

\begin{tabular}{lcccccc}
\hline \multirow{2}{*}{ Boom } & \multirow{2}{*}{ Tension (N) } & \multirow{5}{*}{ Bending moments (N.m) } & $H$ & $h$ & $B$ & $b$ \\
\hline 1 & $F_{N 1}$ & $M_{1}$ & $H_{1}$ & $h_{1}$ & $B_{1}$ & $b_{1}$ \\
2 & $F_{N 2}$ & $M_{2}$ & $H_{2}$ & $h_{2}$ & $B_{2}$ & $b_{2}$ \\
3 & $F_{N 3}$ & $M_{3}$ & $H_{3}$ & $h_{3}$ & $B_{3}$ & $b_{3}$ \\
4 & $F_{N 4}$ & $M_{4}$ & $H_{4}$ & $h_{4}$ & $B_{4}$ & $b_{4}$ \\
\hline
\end{tabular}

$$
\begin{gathered}
l_{1}=\left(a_{01}^{2}+a_{02}^{2}+a_{11}^{2}-2 \cdot \sqrt{a_{01}^{2}+a_{02}^{2}}\right. \\
\left.\cdot a_{11} \cdot \cos \left(\angle O A B+\theta_{1}\right)\right)^{1 / 2}, \\
\beta_{1}=\arcsin \left(\frac{\sqrt{a_{01}^{2}+a_{02}^{2}} \cdot \sin \left(\angle O A B+\theta_{1}\right)}{l_{1}}\right) .
\end{gathered}
$$

3.2. The Other Three Boom Cylinder Models. The other three boom cylinder connection is shown in Figure 3. The luffing mechanism parameters are in Table 2.

\section{Soft Sensor Numerical Model}

4.1. Test Points Tension and Bending Moments. Based on the multibody luffing mechanism connected relationship, the test points' stress soft sensor model of the structure has been built according to Figure 4 . In order to calculate the realistic working conditions, the luffing mechanism joint friction is taken into account as well. And the friction type is Coulomb friction. The tension of the test points is calculated in the appendices ((A.1)-(A.6)). On the other hand, the bending moments are derived from (2) to (4).

As shown in Figure 4, the boom test points' stress can be expressed as in (5).

Here, in Figure $4, F_{i}(i=1,2,3,4)$ is the joints' tension on the boom. $\theta_{i}(i=1,2,3,4)$ is the horizontal angle of boom $i$. The friction circle (dashed circle in Figure 4) radius of boom $i$ is $\rho$. $f$ is the friction coefficient, and $r$ is the joint radius. $\varphi_{i}$ is the front joint force horizontal angle of boom $i . \eta_{i 1}$ and $\eta_{i 2}$ are angles between joints and links. $F_{j 1}^{x}$ and $F_{j 2}^{y}$ are the joint forces between boom 1 and the standoffs. $F_{i}^{g}$ are the cylinder forces of boom $i(i=1,2,3,4) . F_{(i-1) 1}^{l}$ and $F_{(i-1) 2}^{l}$ are joint forces between boom $i$ and the links $(i=1,2,3,4) . G_{i}$, $G g_{i}$, and $G_{i}^{f}$ are the respectively equivalent weight of boom $i(i=1,2,3,4)$, cylinder $i(i=1,2,3,4)$, and boom tip.
The tension and bending moment parameters of the multibody boom structure are shown in Table 3.

As in Figure 5, the boom cross section moment inertia of the $x$-axis can be written as

$$
\begin{aligned}
I_{x} & =\int_{A} y^{2} d A=2 \int_{h / 2}^{H / 2} b y^{2} d y+2 \int_{-H / 2}^{H / 2}\left(\frac{B-b}{2}\right) y^{2} d y \\
& =\frac{1}{12}\left(B H^{3}-b h^{3}\right) .
\end{aligned}
$$

The bending modulus is expressed as

$$
W=\frac{I_{x}}{y_{\max }}=\frac{(1 / 12)\left(B H^{3}-b h^{3}\right)}{H / 2}=\frac{B H^{3}-b h^{3}}{6 H} .
$$

And the test points' cross section area is

$$
A=b(H-h)+(B-b) H .
$$

Here, $h$ and $b$ are the boom cross section internal width and height. Meanwhile, $H$ and $B$ are the boom external cross section width and height.

4.2. Test Points' Stress. Finally, the stress of the test points can be calculated based on the above tension and bending moments by

$$
\sigma=\frac{F_{N}}{A}+\frac{M}{W}
$$

The manipulator test rig parameters values are shown in Table 4

The simulation of the ground and wall conditions is done in Matlab software then. The posture angles of the booms are in Table 5. Figure 6 is the ground and wall working condition postures in the simulation process. 


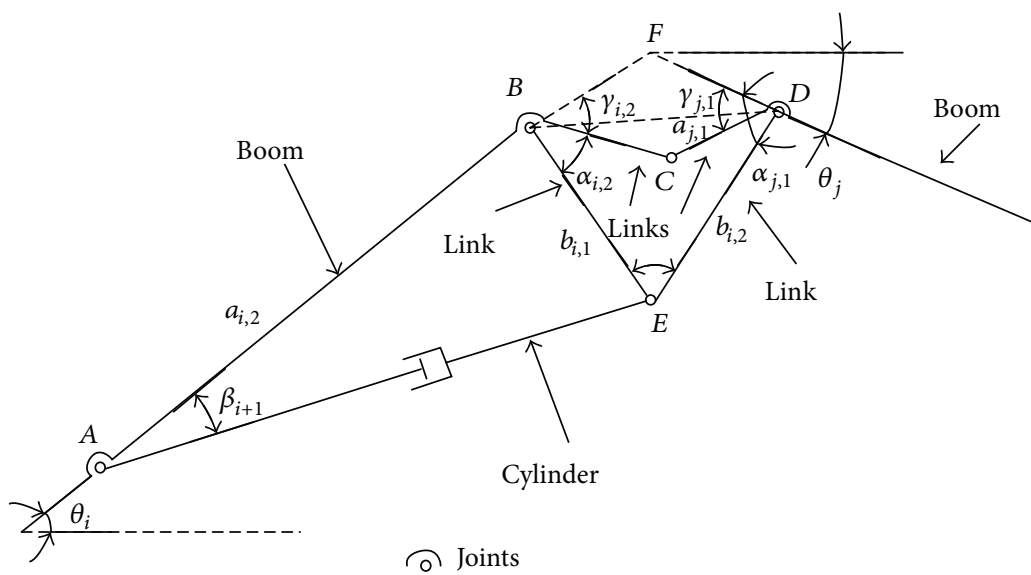

FIGURE 3: Connection relationship of the other three booms, links, and hydraulic cylinders.

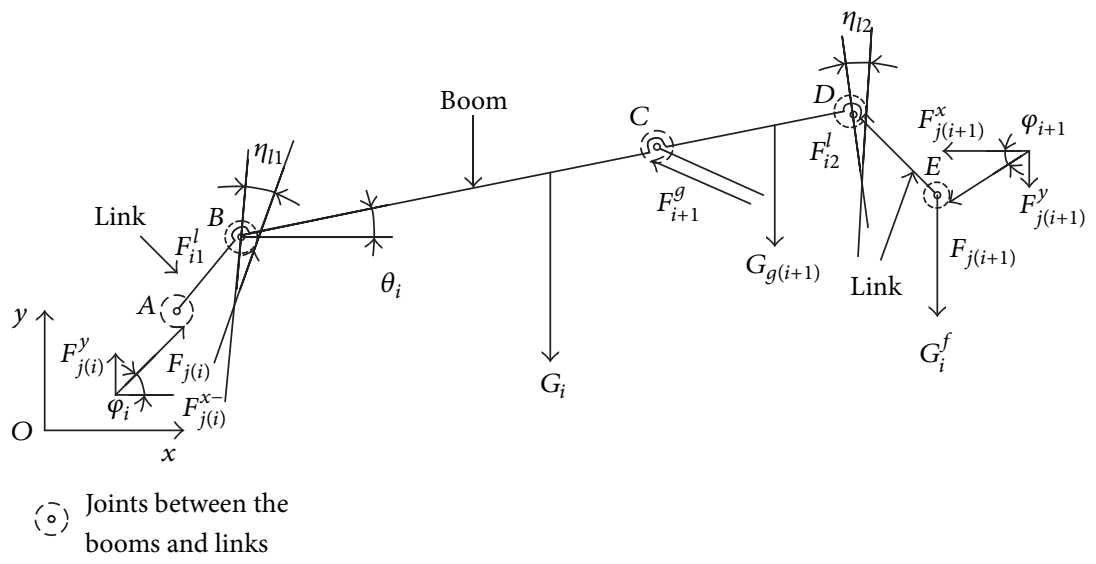

FIgURE 4: Boom tension calculation considering joints Coulomb friction.

TABLE 4: Boom test rig parameters value.

\begin{tabular}{lc}
\hline Parameters & Value \\
\hline Boom weight & $886.3 \mathrm{~N}, 371.42 \mathrm{~N}, 313.6 \mathrm{~N}, 179.34 \mathrm{~N}$ \\
Boom length & $3.76 \mathrm{~m}, 2.83 \mathrm{~m}, 2.88 \mathrm{~m}, 3.21 \mathrm{~m}$ \\
& $a_{01}, a_{02}: 0.13 \mathrm{~m}, 0.24 \mathrm{~m}$ \\
Joint distance & $a_{11}, a_{12}, a_{13}: 0.65 \mathrm{~m}, 1.09 \mathrm{~m}, 0.24 \mathrm{~m}$ \\
between booms & $a_{21}, a_{22}, a_{23}: 0.25 \mathrm{~m}, 0.67 \mathrm{~m}, 0.126 \mathrm{~m}$ \\
& $a_{31}, a_{32}, a_{33}: 0.135 \mathrm{~m}, 0.7 \mathrm{~m}, 0.12 \mathrm{~m}$ \\
& $a_{41}: 0.14 \mathrm{~m}$ \\
Boom bending angles & $\gamma_{12}: 0.36 \pi ; \gamma_{21}, \gamma_{22}: 0.278 \pi, 0.278 \pi$ \\
& $\gamma_{31}, \gamma_{32}: 0.294 \pi, 0.294 \pi ; \gamma_{41}: 0.3 \pi$ \\
Links length & $b_{11}, b_{12}: 0.4 \mathrm{~m}, 0.39 \mathrm{~m}$ \\
& $b_{21}, b_{22}: 0.18 \mathrm{~m}, 0.15 \mathrm{~m}$ \\
Cylinders weight & $b_{31}, b_{32}: 0.24 \mathrm{~m}, 0.23 \mathrm{~m}$ \\
Links weight & $144 \mathrm{~N}, 180 \mathrm{~N}, 74.5 \mathrm{~N}, 24.5 \mathrm{~N}$ \\
\hline
\end{tabular}

\section{Experiment and Simulation Analysis}

5.1. Experiment. In order to verify that the proposed method is reasonable and that the established soft sensor model is
TABLE 5: The boom angles of the two working conditions $\left({ }^{\circ}\right)$.

\begin{tabular}{lcccc}
\hline Working condition & Boom 1 & Boom 2 & Boom 3 & Boom 4 \\
\hline Ground & 73 & 18 & -27 & -67 \\
Wall & 58 & 45 & -2 & -70 \\
\hline
\end{tabular}

correct, an experiment has been done on a test rig. The main instruments are as follows.

(a) Dynamic data acquisition instrument: the Dewesoft data acquisition is adopted as in Figure 7. It has 16 input and output channels, 6 acceleration channels, and 2 CAN modules. The collected pressure, displacement, strain, and data can be got and postprocessed in it.

(b) Angle sensor: the SANG5000 angle sensors (see Figure 8) are used too. Each angle sensor is pasted onto one boom so the angle signals can be got then.

(c) Strain sensor: strain sensors are used to test the selected points' stress. The strain sensors pasted on 


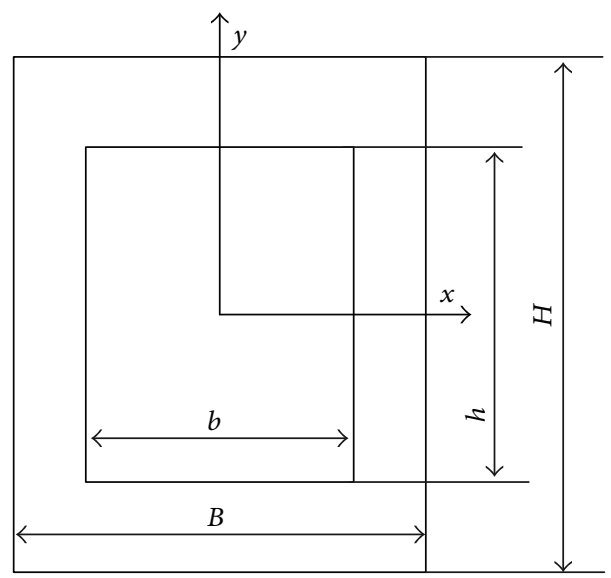

FIgURE 5: Boom cross section parameters.

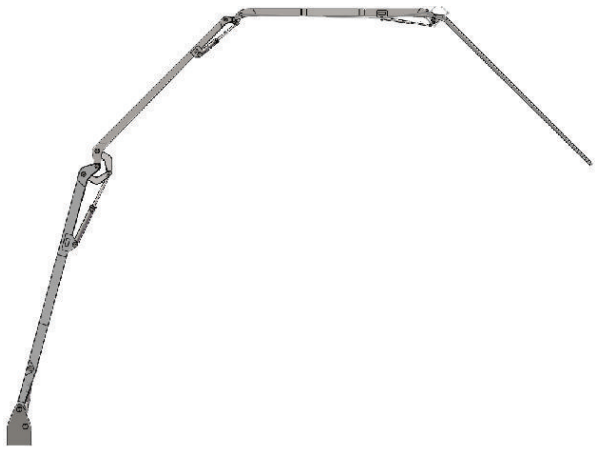

(a)

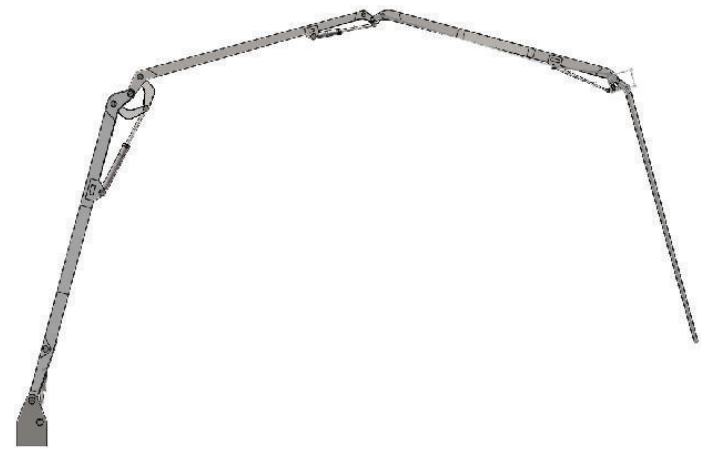

(b)

FIGURE 6: Manipulator postures of ground condition (a) and wall condition (b).

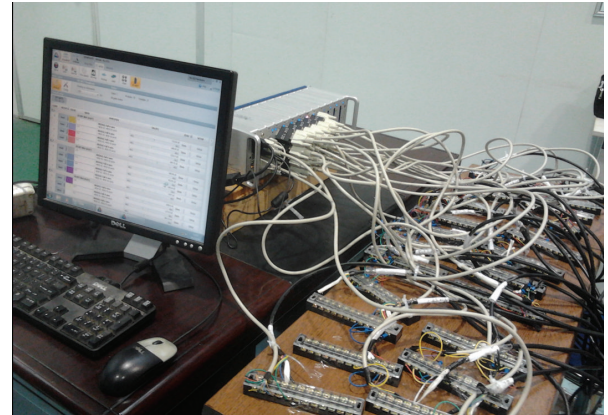

FIGURE 7: Dewesoft data acquisition process instrument.

the four booms are as in Figure 9. And Figure 10 is the strain sensor pasted onto the supports.

(d) Truck mounted concrete pump boom test rig: the $13 \mathrm{~m}$ truck mounted concrete pump boom test rig (see Figure 11) is used either. Each boom is separately driven by a hydraulic actuator.

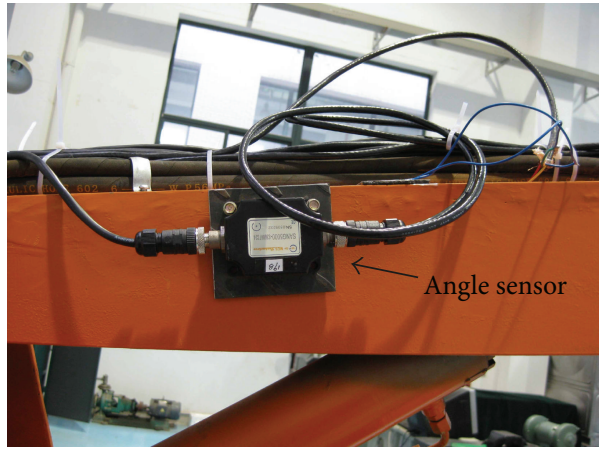

Figure 8: Angle sensor pasted on boom 1 during the experiment.

5.2. Experiment and Simulation Comparison. The test points' stress simulation and experiment results of the ground and wall conditions are shown in Figure 12.

As can be seen in Figure 12, the test points' stress results of the two conditions agree well between experiment and numerical model. The maximum stress test value of the ground condition in Figure 12(a) is $100 \mathrm{Mpa}$ on test point 1. 


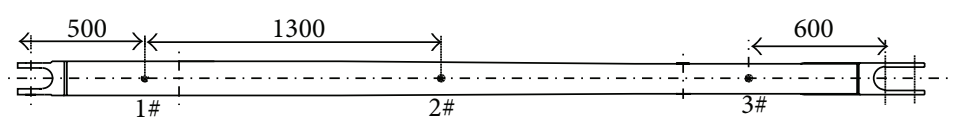

(a)

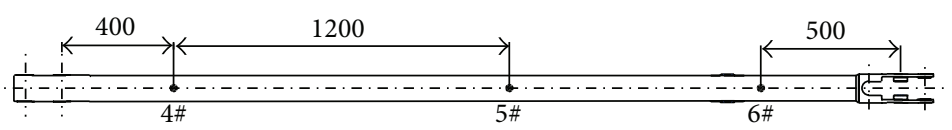

(b)

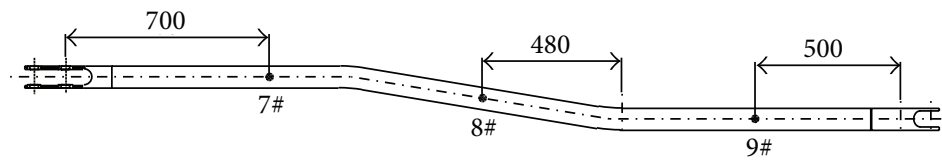

(c)

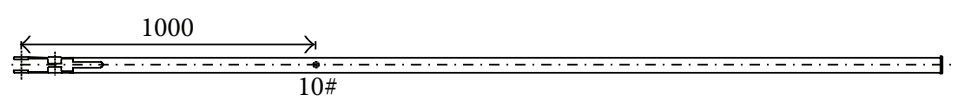

(d)

FIGURE 9: Strain sensors of the test points pasted on boom 1 (a), boom 2 (b), boom 3 (c), and boom 4 (d) during the experiment.

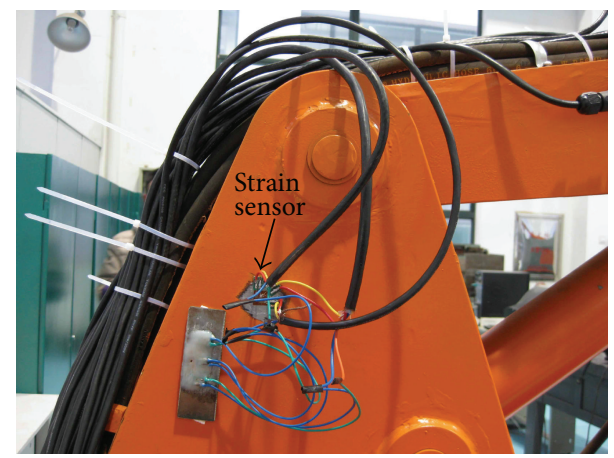

FIGURE 10: Strain sensor pasted on the supports during the experiment.

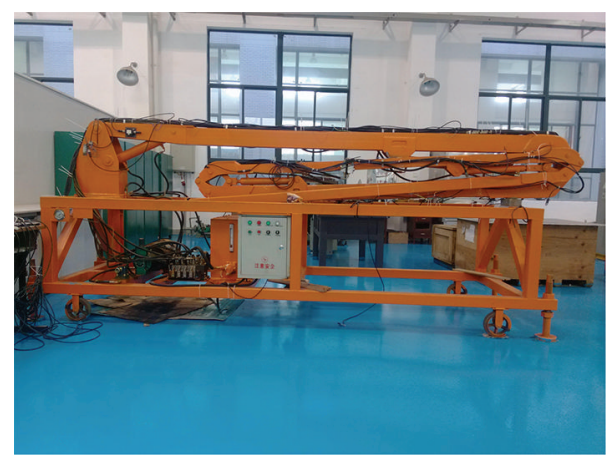

FIGURE 11: The multibody boom test rig.

Compared with the simulated value $95 \mathrm{Mpa}$ of test point 1 , the error between them is about $5 \mathrm{Mpa}$. And the largest error in this condition between them is about $10 \mathrm{Mpa}$ on test point 7. The other points' results are both in good agreement.
The maximum test value of the wall condition in Figure $12(\mathrm{~b})$ is $84 \mathrm{Mpa}$ of test point 1 . Compared with the simulated values $82 \mathrm{Mpa}$, the error between them is $2 \mathrm{Mpa}$. And the largest error in this condition is about $10 \mathrm{Mpa}$ on test points 6 and 7 . The other points are both with good agreement in this working condition too.

The maximum stress of both the two conditions is smaller than the allowable stress $230 \mathrm{Mpa}$ of the boom structure. In the simulation process, the booms uniform mass is considered as concentrated mass; besides, the cross section area is regarded as uniform beam instead of nonuniform beam and the booms' center of gravity moves backward in the numerical model. Therefore, the errors are inevitably. So, the soft sensor model established is correct and rational. Meanwhile, it is feasible and convenient to use angle signal to obtain stress of different postures.

\section{Conclusion}

Large-scale multibody manipulator stress value is difficult to obtain during the long-time working process. But the boom angle information is easy to measure and the stability and lifespan of angle sensors are better than strain sensors. By analyzing the mathematical relationships between the angle and the strain information, a soft sensor model has been established. In the model, the joint Coulomb friction is considered too. Then, the stress value can be obtained conveniently by angle signals of the booms. The stress results calculated by the model agree well with the experimental ones of the ground and wall conditions. Thus, the long-time signal acquisition will be feasible and the working efficiency will be improved. Next, by comparing the experimental and numerical results, it is proved that the soft sensor model of the test rig is correct. This provides help for long-term health monitoring for such manipulators and greatly reduces cost. 


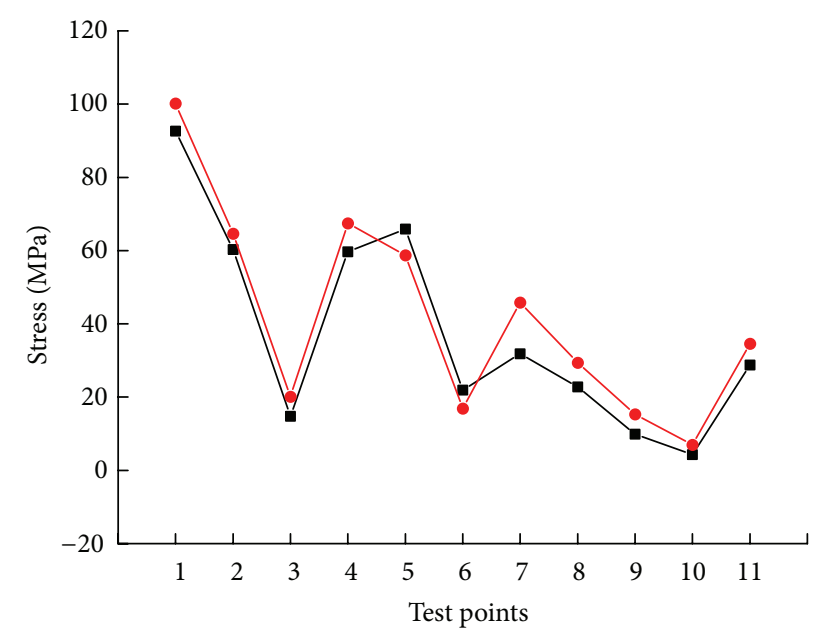

$\rightarrow-$ Numerical simulation $\rightarrow$ Test value

(a) Ground condition

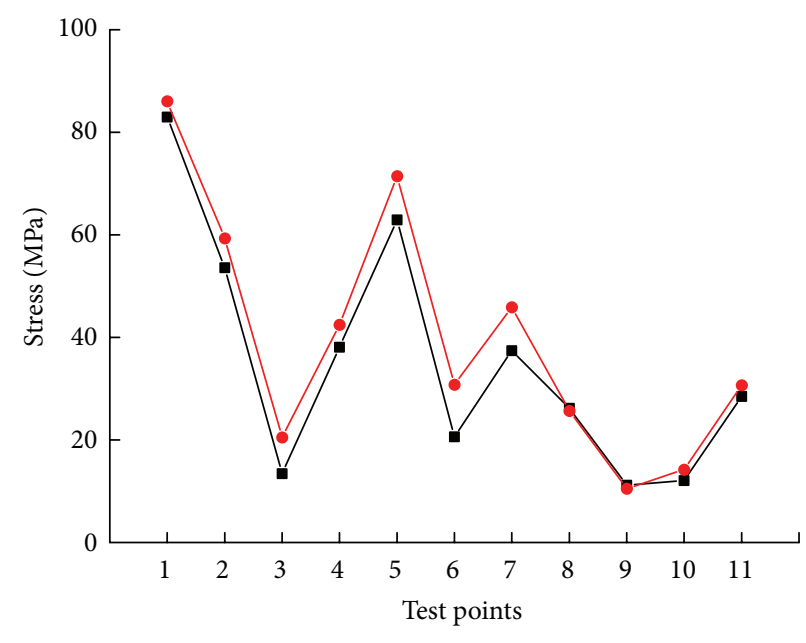

$-\backsim$ Numerical simulation

$\rightarrow$ Test value

FIGURE 12: Stress comparison between test and numerical results of the boom.

\section{Appendix}

\section{Test Points Tension Calculation}

As to DC section in Figure $4\left(0<x \leq a_{i, 2}\right)$, when $x \leq a_{i 2}-l_{i+1}$ :

$$
\begin{aligned}
F_{N(i)}=-( & F_{j(i+1)}^{x} \cos \theta_{i}+F_{j(i+1)}^{y} \sin \theta_{i}+F_{i 2}^{l} \\
& \left.\quad \times \cos \left(\gamma_{i 2}+\alpha_{i 2}-\eta_{i 2}\right)+G_{i} \frac{x}{L_{i}} \sin \theta_{i}+G_{i}^{f} \sin \theta_{i}\right),
\end{aligned}
$$

$$
\begin{aligned}
M_{i}= & G_{i} \frac{x}{L_{i}} \cdot \frac{1}{2} x \cos \theta_{i}+G_{i}^{f} \cdot x \cos \theta_{i}-F_{j(i+1)}^{x} \\
& \cdot\left(x \sin \theta_{i}+a_{i, 3} \sin \left(\theta_{i}-\gamma_{i, 2}\right)\right) \\
& +F_{j(i+1)}^{y} \cdot\left(x \cos \theta_{i}+a_{i 3} \cos \left(\theta_{i}-\gamma_{i 2}\right)\right) \\
& -F_{i 2}^{l} \cdot x \sin \left(\alpha_{i 2}+\gamma_{i 2}-\eta_{i 2}\right)+F_{i 2}^{l} \cdot \rho-F_{j(i+1)} \cdot \rho .
\end{aligned}
$$

When $x>a_{i 2}-l_{i+1}$ :

$$
\begin{aligned}
F_{N(i)}=-( & F_{j(i+1)}^{x} \cos \theta_{i}+F_{j(i+1)}^{y} \sin \theta_{i} \\
& +F_{i 2}^{l} \cos \left(\gamma_{i 2}+\alpha_{i 2}-\eta_{i 2}\right)+G_{i} \frac{x}{L_{i}} \sin \theta_{i} \\
& \left.+G_{i}^{f} \sin \theta_{i}+G_{g(i+1)} \frac{l_{i+1}-\left(a_{i 2}-x\right)}{l_{i+1}} \sin \theta_{i}\right),
\end{aligned}
$$

$$
\begin{aligned}
M_{i}= & G_{i} \frac{x}{L_{i}} \cdot \frac{1}{2} x \cos \theta_{i}+G_{i}^{f} \cdot x \cos \theta_{i}+G_{g(i+1)} \\
& \times \frac{l_{i+1}-\left(a_{i 2}-x\right)}{l_{i+1}} \cdot \frac{1}{2}\left(l_{i+1}-\left(a_{i 2}-x\right)\right) \cos \theta_{i}+F_{i 2}^{l} \cdot \rho \\
& -F_{j(i+1)} \cdot \rho-F_{j(i+1)}^{x} \cdot\left(x \sin \theta_{i}+a_{i, 3} \sin \left(\theta_{i}-\gamma_{i, 2}\right)\right) \\
& +F_{j(i+1)}^{y} \cdot\left(x \cos \theta_{i}+a_{i 3} \cos \left(\theta_{i}-\gamma_{i 2}\right)\right) \\
& -F_{i 2}^{l} \cdot x \sin \left(\alpha_{i 2}+\gamma_{i 2}-\eta_{i 2}\right) .
\end{aligned}
$$

As to CB section in Figure $4\left(a_{i, 2}<x \leq L_{i}\right)$

$$
\begin{aligned}
F_{N(i)}=-( & F_{j(i+1)}^{x} \cos \theta_{i}+F_{j(i+1)}^{y} \sin \theta_{i} \\
& +F_{i 2}^{l} \cos \left(\gamma_{i 2}+\alpha_{i 2}-\eta_{i 2}\right)+G_{i} \frac{x}{L_{i}} \sin \theta_{i} \\
& \left.+G_{i}^{f} \sin \theta_{i}+G_{g(i+1)} \sin \theta_{i}+F_{i+1}^{g} \cos \beta_{i+1}\right),
\end{aligned}
$$

$$
M_{i}=G_{i} \frac{x}{L_{i}} \cdot \frac{1}{2} x \cos \theta_{i}+G_{i}^{f} \cdot x \cos \theta_{i}+G_{g(i+1)}
$$

$$
\begin{aligned}
& \cdot\left(\frac{1}{2} l_{i+1}+\left(x-a_{i 2}\right)\right) \cos \theta_{i}-F_{j(i+1)}^{x} \\
& \cdot\left(x \sin \theta_{i}+a_{i, 3} \sin \left(\theta_{i}-\gamma_{i, 2}\right)\right)+F_{j(i+1)}^{y} \\
& \cdot\left(x \cos \theta_{i}+a_{i 3} \cos \left(\theta_{i}-\gamma_{i 2}\right)\right)_{i+1}-F_{i+1}^{g} \\
& \cdot\left(x-a_{i 2}\right) \sin \beta-F_{i 2}^{l} \cdot x \sin \left(\alpha_{i 2}+\gamma_{i 2}-\eta_{i 2}\right) \\
& +F_{i 2}^{l} \cdot \rho-F_{i+1}^{g} \cdot \rho-F_{j(i+1)} \cdot \rho, \\
& \rho=f_{v} \cdot r, \quad f_{v}=\left(1 \sim \frac{\pi}{2}\right) f .
\end{aligned}
$$




\section{Conflict of Interests}

The authors declare that there is no conflict of interests regarding the publication of this paper.

\section{Acknowledgments}

This work was supported by State key laboratory of high performance complex manufacturing (no. zzyjkt2013-0613), Central South University, the National " 863 " project (no. 2008AA042801) and National Basic Research Program "973" program (nos. 2010CB731703 and 2012CB619505).

\section{References}

[1] G. Cazzulani, S. Moschini, F. Resta et al., "A diagnostic logic for preventing structural failure in concrete displacing booms," Automation in Construction, vol. 35, no. 11, pp. 499-506, 2013.

[2] G. Hua, Y. Wu, H. Tang, and Z. Zhong, "Damage decoupling analysis of pump truck structure on multi-load," Noise and Vibration Worldwide, vol. 42, no. 11, pp. 20-24, 2011.

[3] G. Cazzulani, C. Ghielmetti, H. Giberti, F. Resta, and F. Ripamonti, "A test rig and numerical model for investigating truck mounted concrete pumps," Automation in Construction, vol. 20, no. 8, pp. 1133-1142, 2011.

[4] X. Sun, H. Ye, and S. Fei, "A closed-loop detection and openloop control strategy for booms of truck-mounted concrete pump," Automation in Construction, vol. 31, no. 5, pp. 265-273, 2013.

[5] J. Liu, L. Dai, L. Zhao, J. Cai, and J. Zhang, "Modeling and simulation of flexible multi-body dynamics of concrete pump truck arm," Chinese Journal of Mechanical Engineering, vol. 43, no. 11, pp. 131-135, 2007.

[6] P. Facco, F. Doplicher, F. Bezzo, and M. Barolo, "Moving average PLS soft sensor for online product quality estimation in an industrial batch polymerization process," Journal of Process Control, vol. 19, no. 3, pp. 520-529, 2009.

[7] L. McElroy, J. Bao, C. T. Jayasundara, R. Y. Yang, and A. B. Yu, "A soft-sensor approach to impact intensity prediction in stirred mills guided by DEM models," Powder Technology, vol. 219, pp. 151-157, 2012.

[8] J. Deng, L. Xie, L. Chen et al., "Development and industrial application of soft sensors with on-line Bayesian model updating strategy," Journal of Process Control, vol. 23, no. 3, pp. 317325, 2013.

[9] J. G. Wang, S. S. Jang, D. S. H. Wong et al., "Soft-sensor development with adaptive variable selection using nonnegative garrote," Control Engineering Practice, vol. 21, no. 9, pp. 11571164, 2013.

[10] H. Fan, Establishment of Low Cycle Stress Soft Sensor Model for Truck Mounted Concrete Pump and Its Application in Fatigue Damage Calculation, Central South University, Changsha, China, 2012.

[11] P. Dario, "A comparison between two force-position controllers with gravity compensation simulated on a humanoid arm," Journal of Robotics, vol. 2013, Article ID 256364, 14 pages, 2013. 

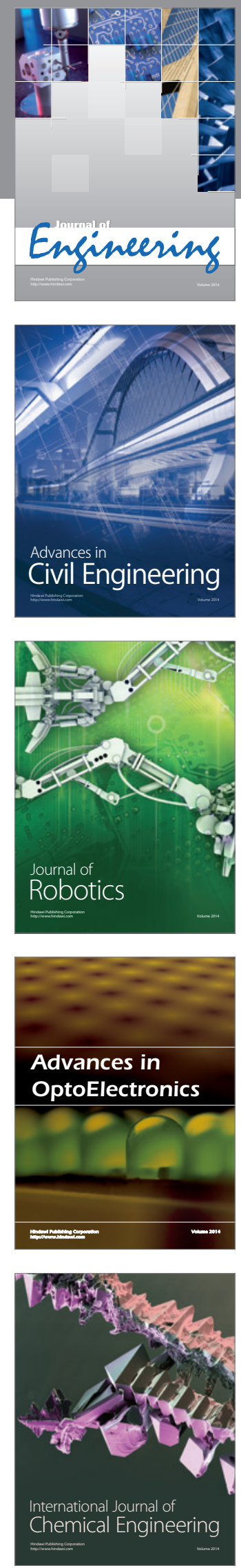

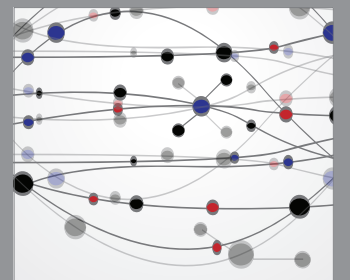

The Scientific World Journal
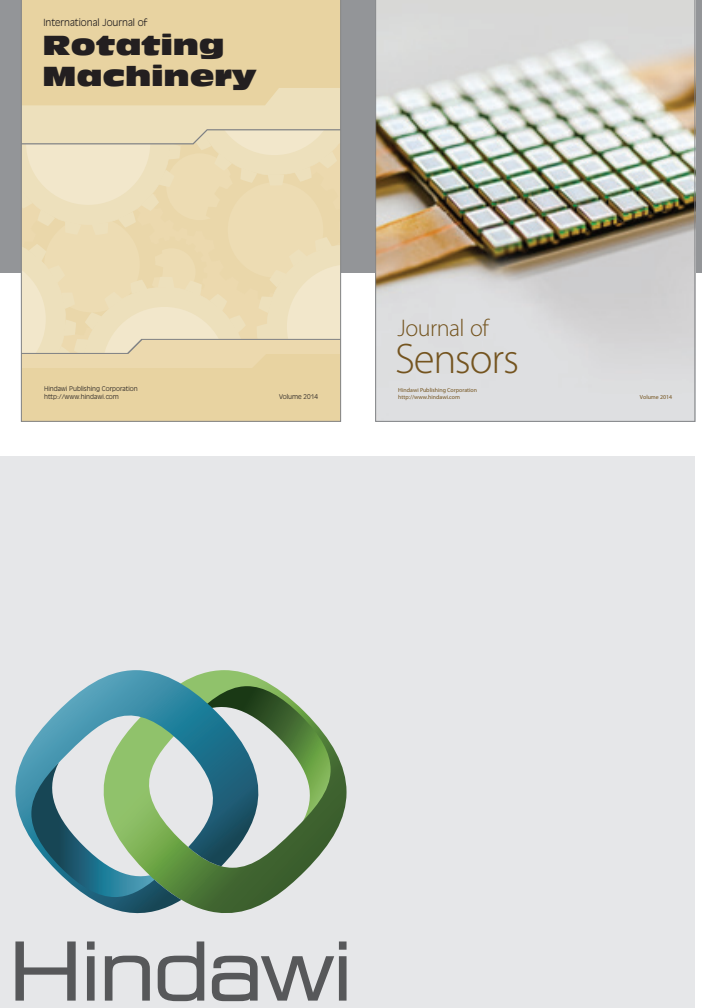

Submit your manuscripts at http://www.hindawi.com
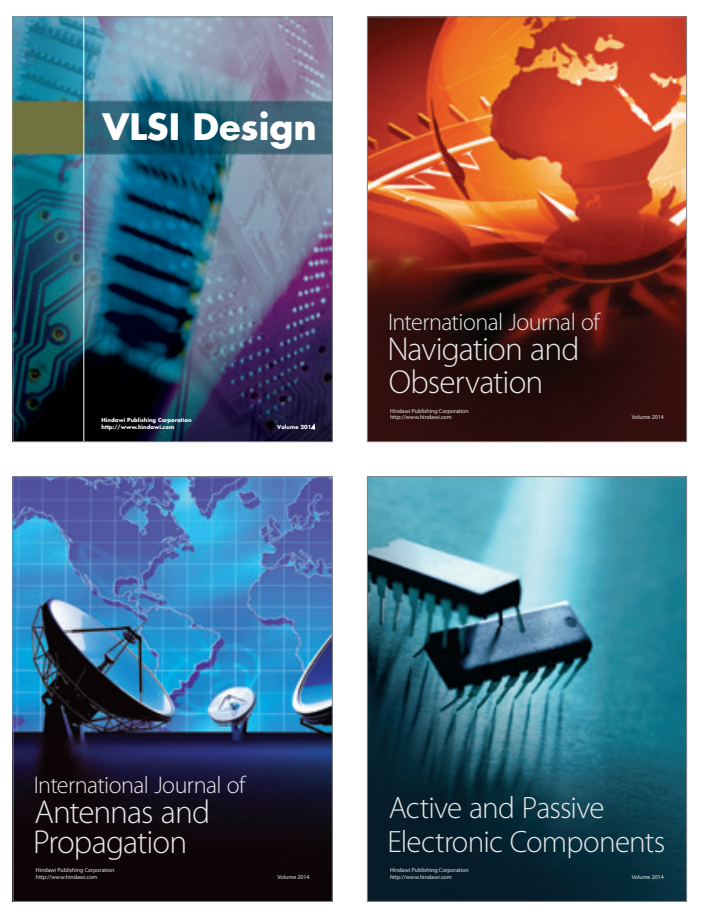
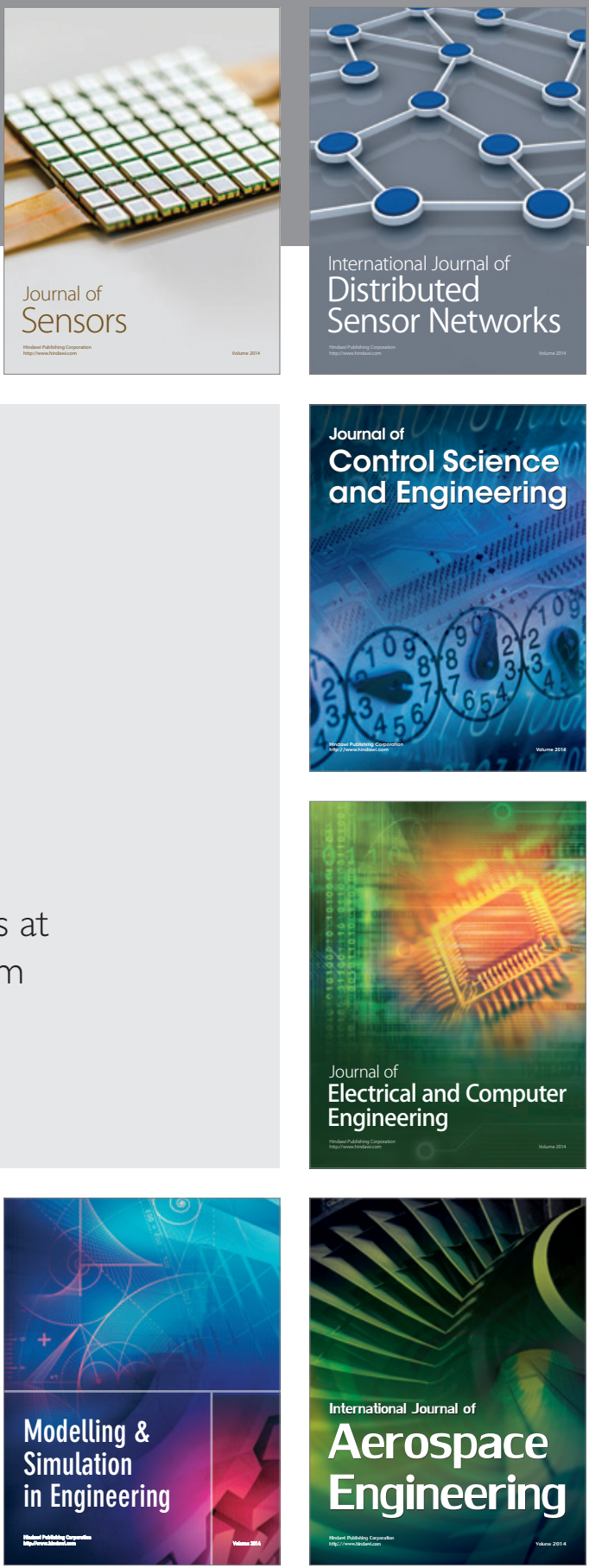

Journal of

Control Science

and Engineering
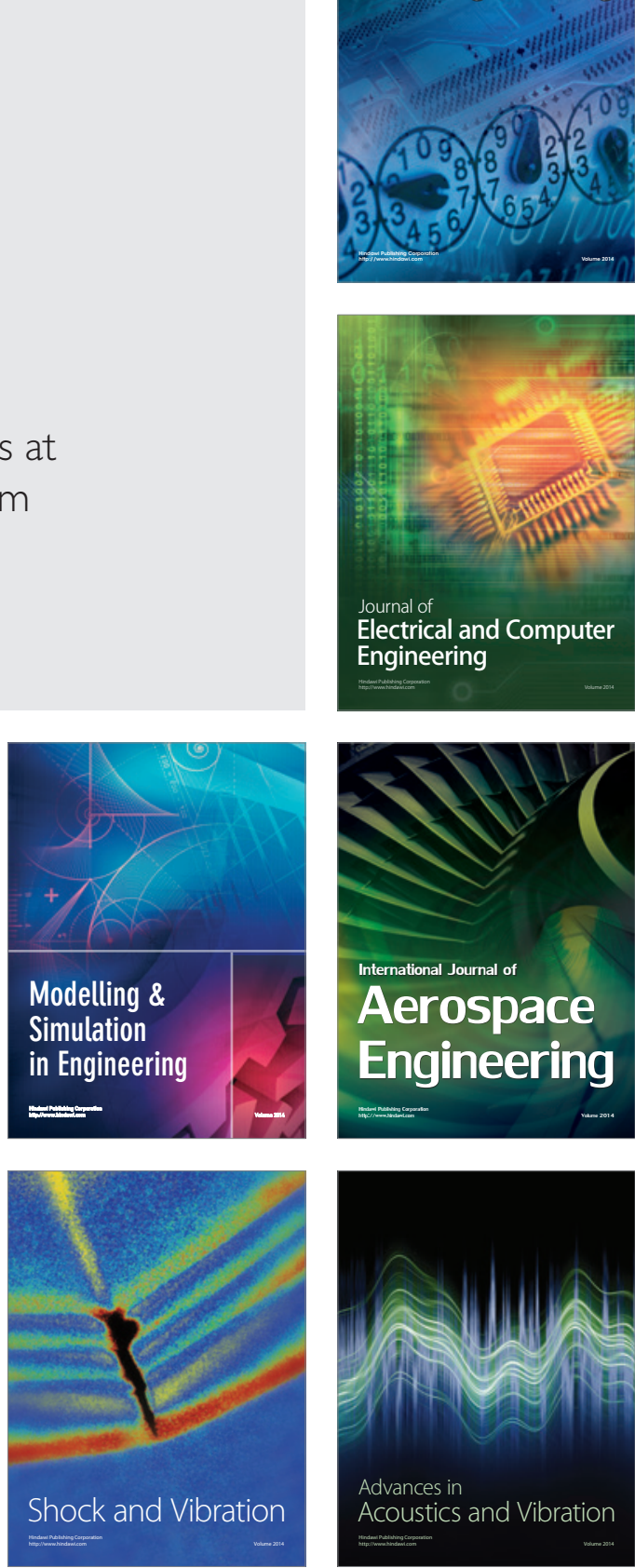